\title{
The Pale Blue Dot and the knowledge systems of science and religion
}

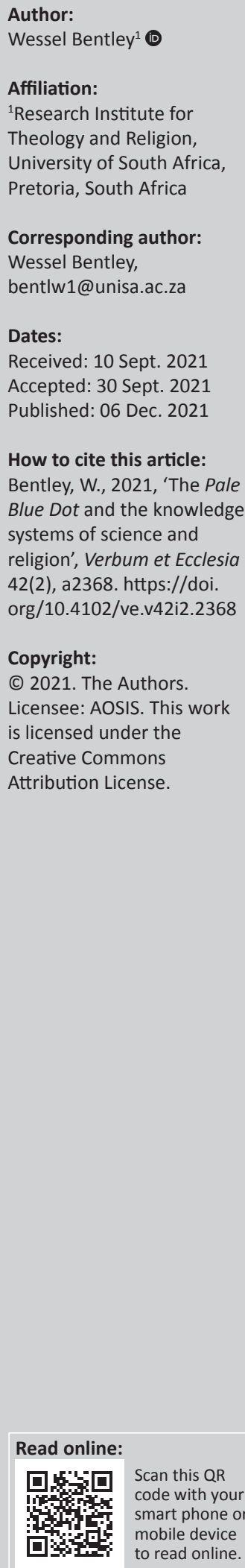

Images, symbols and metaphors are synonymous with the human attempt to makes sense of truths that exceed the limitations of our rigid contextual delineations. In order to comprehend the deeper meanings gained through these tools we are required to employ imagination, cognitive vulnerability, and openness to the idea that there is more to life, reality and meaning than what meets the eye. This article uses the image named Pale Blue Dot as an iconic symbol, exploring the coexistence of science and religion.

Intradisciplinary and/or interdisciplinary implications: This article argues that coexistence and cooperation between science and religion is not only a responsible approach in the search for meaning, but is the ideal that reflects the limitations of our knowledge systems in a universe that far exceeds our current understanding and truth convictions.

Keywords: Pale Blue Dot; epistemology; science and religion; truths; transcendence; metaphor.

\section{Another perspective of ourselves ${ }^{1}$}

Just over three decades ago, on 14 February 1990, while heading towards the outer limits of our solar system, Voyager $\mathrm{I}^{2}$ received an instruction to turn back its cameras towards earth. This was going to be its last glance at 'home'. This came as a request by Carl Sagan, a world-renowned astronomer and astrophysicist. The resulting image, named Pale Blue Dot (PBD) became an iconic picture of earth, showing the planet as a mere speck, embraced by a ray of sunlight. ${ }^{3}$ Sagan (1994) had the following to say about the image:

Look again at that dot. That's here. That's home. That's us. On it everyone you love, everyone you know, everyone you ever heard of, every human being who ever was, lived out their lives. The aggregate of our joy and suffering, thousands of confident religions, ideologies, and economic doctrines, every hunter and forager, every hero and coward, every creator and destroyer of civilization, every king and peasant, every young couple in love, every mother and father, hopeful child, inventor and explorer, every teacher of morals, every corrupt politician, every 'superstar', every 'supreme leader', every saint and sinner in the history of our species lived there - on a mote of dust suspended in a sunbeam. (p. 6)

The image is philosophically rich; it asks of the viewer to not only contemplate the miniscule scale of our experience of life, but to appreciate the complexity, the improbability, the 'miracle' of life, and the phenomenon of life being aware of itself and its surroundings. More so, it is not only an appreciation of life, but the recognition that life has progressed to the point where it can engineer and manufacture instruments that enable it to look back at itself from a vantage point that has never been traversed by any human - we are looking back from a place where we have never been before. The image puts into tangible reality Sagan's notion of the cosmos being aware of itself, expressing its awe and marvel through human thought and ingenuity (See Cummings 2017:17). As much as the image is awe-inspiring, it is also frightening. With a sudden 'wash' of existential crisis, the viewer asks whether it is possible for such a tiny speck to assume to know so much about the universe within which it exists.

Against the backdrop of seemingly empty space, this one speck, one pixel on the photo, is where conscious life (that we know of) is present. The lonely Voyager, an extension of Earth-confined consciousness, took a snapshot of the sum-total of human knowledge, experience, history, and the totality of Earth-bound life and all its processes. The PBD is more than just a speck on a cosmic

\footnotetext{
1.This article is dedicated to Prof. Wentzel van Huyssteen.

2.Voyager I was launched by NASA on 5 September 1977 to explore the outer parts of our solar system. In August 2012, it entered interstellar space, the first human-made object to venture this far.
}

3.For a copy of the image, see https://solarsystem.nasa.gov/resources/536/voyager-1s-pale-blue-dot/ 
photograph - it is a symbol. It speaks of something greater than itself. It speaks of hidden complexity and diversity, concentrated on one (in)significant planet, orbiting a midsized star on the spiral arm of a galaxy, which we call The Milky Way.

From this distance, Earth is this undefined speck. Definition and detail are absent. Dare to zoom in, to move closer, and distinct features become evident. The closer one draws, the greater the details and diversity: A serene, blue dot makes way for patches of land and water, the outline of continents manifest, weather systems are dotted around the globe as white-whirled clouds, geographic features such as mountains and rivers appear, habitable areas in the form of cities and forests sprout up, human and animal populations move around as dots, focussed on their tasks at hand while oblivious to the ponderings of the magnifying observer. Like Sartre's (2000) Antoine Roquentin, ${ }^{4}$ Voyager looks in as these diverse people scurry around while thinking that their lives have any lasting and metaphysical significance. They are, after all, merely organisms on a lonely planet, surrounded by mostly nothing. The deafening sounds of busy city streets dissipate into the expanse of cosmic silence. Sirens fade into nothingness, and so do the songs of birds, the crashing of waves, and the primal cry of a new-born baby.

Lest we get lost in despair, life still needs to be lived, for to embrace cosmic nihilism will lead to insanity or perhaps even suicide, as suggested by Camus (2000:2). To live meaningfully is to embrace the absurd - not only the absurdities that appear in life, but the absurdity of life itself (as Camus further responded to Sartre's Nausea (Camus 2000:13)). Voyager 'Roquentin' zooms in even further focussing on the human species and finds that diversity only increases on this seemingly PBD. It finds nothing homogenous about this species. Instead, it unearths racial diversity, culture, religion, language, dialects, genetics, and so on. In the midst of all this complexity, we find the innate human desire for understanding itself and its surroundings. Expressed through language, culture and different forms of symbolic representations, humanity employs (for the purposes of this article) two dominant knowledge systems - as broad categories, defined as science and religion. ${ }^{5}$ The observer discovers that instead of these knowledge systems drawing alongside one other in a common effort to attain perspective, ${ }^{6}$ they have a rich history of each claiming to be sometimes the sole custodian of objective (and perhaps

4.Antoine Roquentin, a character in Sartre's (2000) novel Nausea, is a narrator who is struck by the awareness of humanity's overindulgence in its own existence and meaning.

5.Science and religion are used as generic terms in this article. The subdisciplines of science and the varied religious expressions do make for complex arguments that may happen to be contradictory to the arguments posed in this article. The reade is invited to view science and religion from the perspective of Voyager I, namely that on the PBD, science exists as the human attempt to understand the laws and physical attributes of the detectable cosmos, while religion is the human search for physical attributes of the detectable cosmos, while religion is the human search for meaning in light of existence within this cosmos. Both these knowledge systems human perception of self and its environment.

6.I prefer to use the term 'perspective' as opposed to notions of 'truth', 'certainty', or even 'knowledge'. The reason being that any expression of insight is done from certain perspective within a particular context. I maintain that this is congruent with expressions given in both science and religion. absolute) truth, with very few examples of synergistic cooperation. The question we therefore ask is: Is it possible for science and religion to offer humanity an adequate selfunderstanding and comprehension of the cosmos within which it exists?

In answering this question, this article, using the PBD as a backdrop, will focus on the following points:

- The dynamic nature of science and religion as knowledge systems.

- Science and religion's respective dependence on, and use of, metaphors to convey knowledge.

- Forming a new language that will embrace what science and religion have to offer in the common quest for meaning.

\section{The dynamic natures of science and religion}

As we have to contend with the fact that a reference to, for instance humanity on the PBD has to be accepted as a generalised blanket-term referring to a specific group of organisms - and can by no means be taken as a static and allencompassing description thereof - so too it is proposed that science and religion exist as notions suspended in their own states of fluidity. Much has been written about the relationship between science and religion. Names such as Barbour, Gould, Van Huyssteen, Johnson, and others are synonymous within this field. In their own way, they have each offered models for these two knowledge systems to engage one another constructively, thus, exploring the possibility that the cooperation between science and religion will be found in a move away from rigid fundamentalisms (and the caricatures of each other as fundamentalist sources of insight) in exchange for a more open and fluid understanding of their own and the other's positions. This does not mean that science and religion are devoid of distinctive features, or that these should be discounted in favour of integration. Science and religion as knowledge systems, bring unique approaches to the table in the search for understanding. They are eloquently summarised and described by Raman (2004):

Science is the human mind's quest to unravel the workings of the world. It is a collective effort to understand, explain, and grasp the perceived world. Religion is a search for meaning behind human existence, and a yearning to connect with the Whole. It arises from the recognition of the uniqueness of consciousness in the universe. Science and religion are the loftiest expressions of the human spirit. (p. 409)

Gleiser (2014) described science and religion as respective instruments of knowing. These instruments shape the way we relate to the world. In his words: '... we could say that religious myths attempt to explain the unknown within the unknowable while science attempts to explain the unknown with the knowable' (Gleiser 2014:3). From a distance, there seems to be no conflict or potential disharmony between these two knowledge systems. Why should there be, for the one seeks to ask the 'How?' questions (science), while the other explores the 'Why?' questions (religion). The complexity of the relationship 
between science and religion cannot be reduced to such simplistic redactions of their nature of enquiry.

Science and religion both seek to address questions pertaining to their interpretation of reality, joining the proverbial dots of self, the other and the context in which these exist. In finding cohesion amongst the infinite points of experienced reality, both science and religion express a notion of having some grasp (however cosmically infantile) on the meaning of life and all its processes. This claim elicits a sense of authority, which in turn demands respect from those who are offered their respective nuggets of knowledge and wisdom. Respect is earned and cannot in fact be demanded. The respect of both science and religion is attained in the nature of their inquest being believable. For science and religion to be believable, they both need to have a measure of rationality $^{7}$ (Van Huyssteen 1988a:862), the language of human understanding. When science and/or religion is received and adopted without critically engaging their respective ontological or epistemological assertions, they can be adhered to and seen as universal and absolute in their respective truth claims. Here, science and/or religion becomes static; and even when new knowledge is presented, neither science nor religion will be amenable to change. Such foundational approaches in science and religion are indicative of bad science and bad religion.

Rationality pivots on critical thinking. Static knowledge is irrational for it denies the dynamic nature of time, space, experience, context, and belief. For this reason, Van Huyssteen, amongst others, calls for critical realism (Van Huyssteen 1988b:250) in both science and religion, not for the sake of offering alternative, contesting perspectives, but in recognition that such engagement, is a responsible way of exercising science and religion.

Perhaps critical reasoning can be the common factor that makes science and religion such important knowledge systems in the way humanity on the PBD interpret their reality (Van Huyssteen 1988b:250). This said, even in the expression of critical reasoning, ardent adherents to science and religion, respectively, may lay claim to a perceived hierarchy of what is deemed to be valid knowledge. Disciples of science, while recognising the importance of religion, may claim that scientific knowledge is objective and concrete, while religious knowledge is subjective and filled with untestable presuppositions (Green 2011:30). In turn, adherents of religion may claim that their faith supersedes scientific knowledge, the same scientific knowledge that offers them the luxuries of technological advancement in medicine and other segments of their daily lives. ${ }^{8}$ To them, God comes first and then science, faith, and knowledge.

7.Borrowing from Barbour (1971:170), Van Huyssteen states that the "supreme value that determines rationality (in science and religion) is intelligibility' (Van Huyssteen 1988a:848).

8.In the current COVID-19 pandemic, it is notable how many Christians, for instance, hold to the idea that vaccinations are the sign of the Beast, and avoid being vaccinated in favour of a belief that God will protect them from any looming infection. People would rather not offend God (by subjecting themselves to the infection. People would rather not offend God (by subjecting themselves to the
sign of the Beast) than listen to science, which offers a fighting chance against this disease.
Voyager Roquentin looks on at the PBD and shakes its metaphorical head. Can the inhabitants of this lonely planet not see that science and religion are tools, immersed in a common context? This in itself should be reason enough to avoid, or at least limit, 'universalistic claims and assertions of certainty' (Peterson 2008:467). While it is irrational to adhere to siloed, foundational knowledge systems, and equally absurd is to deny their respective value (Green 2011:31), it would be in the common interest of those seeking knowledge to adopt a far more interdisciplinary approach in coming to grips with the context in which they find themselves (Green 2011:27). One has to break down entrenched and rigid disciplinary walls in order to fashion a common understanding that allows for a diverse articulation of rationality in all its forms. To this end, Van Huyssteen in his transdisciplinary approach seeks to do exactly as Peterson (2008:467) mentioned (as above).

The PBD is in motion. Not only does it move physically through the expanse of space, but it is abuzz with conscious life trying to understand itself. This life explores different avenues of knowing and in doing so it must be true to its dynamic context by allowing its knowing to shift as well. The more it does so, the more it is able to articulate its understanding. Knowledge grows exponentially and the last thing these inhabitants can afford is to become static in their method of knowing. This in itself will be the cause of selfannihilation, by becoming irrelevant in a dynamic universe. As the PBD is a manifestation of evolutionary processes, the epistemological approaches of science and religion also need to be evolutionary in nature as well, if for no other reason but to avoid fundamentalisms (Peterson 2008:469), and in turn, to reject metaphoric ontological suicide.

\section{Knowledge based on metaphors}

Further to critical realism being a 'common ground' in responsible practices of science and religion, the admission that neither science nor religion can offer raw, unaltered, uninterpreted knowledge, should be cause enough to leverage some humility in their respective truth expressions. To this end, science and religion use a common language to convey their truths; they are dependent on the language of metaphor. Van Huyssteen (1988b:253) identified this common tool by stating that whether we speak of atoms and molecules or the theories of atonement, metaphors play a vital role in our understanding.

Metaphor exists as a linguistic device in surface language, but the ability intentionally to produce a semantic anomaly in order to suggest a new meaning finds its origin in a cognitive process. Metaphors bear witness to the ability of the human mind to consider and represent new hypotheses. (MacCormac 1983:56-57)

Even at their most basic level, words and thoughts are metaphoric (Reinstorf 2003:191) - language is metaphoric, for the words we use represent something other than itself. It demands context in which these words and thoughts are given their meaning. If this holds true, then knowledge can never be static, for the metaphoric tool that is used to express 
it creates a Möbius strip, asking whether we construct our reality based on our employed knowledge system, or whether we use knowledge systems to describe our reality. MacCormac (1975:406) made another observation about metaphors: 'Many metaphors begin as shocking suggestions and, then, after we become familiar with them, they become more expressive and finally end up as everyday expressions of our language'. Words and concepts such as 'evolution', 'heliocentrism', 'genetic modification', 'sin', 'salvation', and even 'God', all have evocative origins. Yet, each of these 'metaphors', now in common use, 'provide epistemic access to entities that could not have been known otherwise' (Van Huyssteen 1988a:849).

Metaphors themselves are dynamic and are subject to critical scrutiny. Take for instance how religious metaphors referring to God exclusively in the masculine (e.g. Father, King, Son, Shepherd and Lord) have come under question in the context of gender-justice (Tracy 1978:95). The alternative metaphors, for example, 'Parent', 'Comforter', and 'Mother' evoke new responses and build towards a more refined language of the 'One who cannot be described'. Knowledge is a progressive scaffolding of metaphors, adding detail that makes the concepts of investigation more and more refined. In both science and religion, metaphors are constructs that link an 'entity' (whether it be physical or metaphysical) to human understanding. They provide a bridge between the observer and the 'observed'. To extend the metaphor, metaphors are suspension bridges, existing in tension between the observer and the 'observed'. This tension is described as metaphors' reducibility to being a literal paraphrase of that which is 'observed'. Where metaphors are completely reducible to being literal paraphrases, they cease to be metaphors, while if they are completely irreducible, these metaphors will not be understandable (MacCormac 1975:403).

Metaphors exist in a symbiotic, interdependent relationship within both science and religion (Beukes \& Koekemoer 1993:601). It gives humanity access to knowledge systems (as constructs) that express the quest for transcendence - a recognition that there is more to life than animalistic survival, but that the context in which life is experienced is filled with endless possibilities, only limited by the confines of human imagination (Van Huyssteen 2010:149). This is not to say that what is understood by means of science and religion can be reduced as mere imaginary exploration, but should be seen as that which 'grounds' and informs humanity as inquisitive sojourners in the contexts where this knowledge is constructed (Van Huyssteen 1988a:847).

Whether we refer to science or religion as concrete knowledge systems or as vehicles for metaphoric self-understanding, neither science nor religion are ends in themselves. At best, they can be described as means through which the universe is able to speak about itself, specifically the self as manifest in the human experiences of consciousness and life.

Voyager Roquentin observes the PBD and humanity's attempt to give expression to its self-understanding. It is evident that the dualism that exists between the symbolic self and the other (whether it be the object of inquiry, context or belief), has defined the nature of being and knowing on this lonely planet (Holley \& Shearing 2017). This selfunderstanding depends on knowledge systems that can bridge this gap, knowledge systems that in turn rely on metaphors to construct realities that are congruent with what is learnt through observation, experience and belief (Du Toit \& Spangenberg 2002:1140).

\section{Is there a new language?}

Voyager Roquentin stares at the PBD from far away, mesmerised by the playing out of science and religion in offering 'answers' to questions of identity, existence of self and the other. The epistemological premise of rationality in both science and religion, as described in the second section of this article, tends to become the very factor that hampers the quest for knowledge. Science and religion can become so logical and believable that it becomes difficult for the observer (adherent) to consider other truth claims that exist outside their specific frame of reference. The questions raised and posed to science and religion are indeed enquiries formulated by means of critical rationality, but if it is isolated as primarily a cognitive relationship between the observer and the 'observed', it fails in its attempts to enhance the understanding of meaning. It fails, for the observer is not a logical machine, but human, owning more than the capacity to engage cognitively with itself and its context. That which makes us human is to have an enmeshed rationality that fuses with our convictions (Van Huyssteen 2006:133), and dare we add imagination, emotion and subjective immersed experience.

Perhaps a language of knowledge that is true to the common context in which science and religion find themselves should first start off in our more primal responses to stimuli (and not depend solely on cognitive reasoning). Loubser (2015) made important observations in this regard. He suggested that, first, 'by engaging in the arts, we can learn how to reframe and reinterpret our view of the world' (Loubser 2015:3). The arts do not replace science or religion, but assist us in thinking abstractly, that life and the experience thereof cannot be framed within the limits of scientific and religious knowledge systems alone. Even if one were to employ all the knowledge offered in both science and religion in a single life, it would be a life devoid of wholeness. It would be a life stuck between the worlds of empiricism and metaphysics. The experience of life and how we relate to our world is a conglomerate of our mediated experiences of life and the interpretations of these experiences, which are offered mostly by science and religion (Van Huyssteen 2006:134). Life is first experienced and then, it is described. Meaning is first experienced and then, it is sought.

Loubser's second point is that critical thinking cannot depend solely on rationality (and believability), but must be accompanied by the observer's capacity for empathy (Loubser 2015:4-5). In order to avoid being stuck in a specific knowledge system, the observer must show an ability to 
make sense of another's truth, while holding on to their own. Empathy therefore becomes foundational in a true attempt to engage in transdisciplinary studies. ${ }^{9}$

What about other emotions? It is interesting that in descriptions of specifically scientific enquiry (which carries a caricature of being cold, sterile and objective), the premise for such questioning stems from emotional responses such as 'wonder and amazement' (Cummings 2017:19), 'awe' (Johnson et al. 2019:8-9) and curiosity. In religion, being confronted by the magnitude of a God-experience, elicits the same response as offered by Thomas: 'My Lord and my God!' (John 20:28). These are all very emotively based. Besides rationality and the use of metaphor in both the religious and scientific knowledge systems, we can thus also add emotion.

Rationality, metaphor and emotion become the mediatory ground that enables science and religion to come together, each offering their own contributions, but presenting more immersed, contextual truth claims. Where the risk is taken to allow these mediatory elements to facilitate transdisciplinary engagement, we find that the lines that differentiate the stark differences between science and religion become blurred. Johnson et al. (2019), studying scientists' attitude towards religion, observed that many scientists do not adhere to a picture of God as the authoritarian cosmic dictator as proclaimed by many theistic expressions, but describe their belief in God as the awe-inspiring complexity of the cosmos that for them can best be known through the vehicle of science (Johnson et al. 2019:8-9). On the other side of the spectrum, Wheeler propagated a form of religious naturalism, where there is no need for supernatural anthropocentric figures to control the universe, but that spirituality is contextual, and one finds God in the very depths of nature (Wheeler 2017:8) with all its attributes that are 'subject' to the laws of physics. Critics of religion, such as Richard Dawkins are correct in their assessment that: 'The metaphorical God of the physicists is light-years away from the interventionist, miracle-working, thought-reading, sin-punishing, prayeranswering God of the theists and of ordinary language' (Dawkins 2003:64). Dawkins should have added to this sentence '... God of the fundamentalist theist and of ordinary language', for the kind of theism he describes is stuck in a premodern religious knowledge system. Although such forms of religious expressions still exist, there also exists a new wave of religious awareness that takes adapted worldviews and knowledge seriously as offered by scientific enquiry. The combative nature of the New Atheists is as counterproductive as the forms of religious fundamentalism that take no cognisance of the scientific project (Scheitle \& Ecklund 2015:30).

Is it possible that science itself can lead us to forms of reverence and awe that are 'hardly tapped by the conventional

9.Loubser differentiated between transdisciplinary studies and interdisciplinary studies in the following way (referring to the work of Thomas Jahn): ' studies in the following way (refering to the work of Thomas Jahn): “. transdisciplinary researchers intend to integrate knowledge in the overlappin areas between academic questions and important social problems where interdisciplinary researchers intend to integrate knowledge in the overlapping areas between various disciplines' (Loubser 2015:2) faiths' (Peacocke 2004:407; Sagan 1994:50)? In turn, is it possible that religious knowledge systems can lead science to engage with nature in ways immersed with reverence and respect (as found in religious expressions) (Ruse 2005:286)? What about engaging religion in finding solutions to problems that were for far too long only left to the gift of science to solve? What role can religion and spirituality play in global problems such as climate change (Simpson \& O’Reilly 2014:1-6)?

There is no doubt that both science and religion aim to 'tell as true a story as possible' (Peacocke 2004:392-393), using the epistemological tools that inform their ontologies. At the beginning of this article, the question was asked whether it is possible for science and religion to offer humanity an adequate self-understanding and comprehension of the cosmos within which it exists. This article concludes that the answer is a resounding ' $\mathrm{No}^{\prime}$ if science and religion are siloed, immovable and absolute disciplines. It would be ignorant, however, to discount the differences that exist between science and religion. The answer turns to a conditional 'Yes' when it is considered that both science and religion are as dynamic as their context while anchored in critical rationalism, that they are dependent on pliable metaphors for their self-expression, and have to be grounded in the immersed experience of life, which includes aspects of human life which are fundamental to be, such as emotion (especially empathy).

\section{Conclusion}

Voyager 1 is fast moving beyond the reaches of our solar system. This is making it increasingly difficult to communicate with this Earth-made object. It will soon be rendered useless, a floating piece of metal that no longer has any communicative link with its place of origin. To Voyager 1, the PBD is becoming smaller and smaller, soon to become a tiny speck in its night sky. The further it moves away, the more difficult it will be to spot the PBD. Where there once was home, Voyager 1 will only see darkness. This does not mean that the search for meaning on PBD is negligible. Voyager Roquentin will remember what once was home. It will recall how on this tiny speck, a species conscious of itself and of its surroundings, fashioned it out of raw materials found on this planet. Their purpose for creating it was to answer their questions about themselves and the cosmos. Voyager Roquentin fulfilled the task it was designed to do and so much more. It gave humanity a scientific glimpse of their planetary neighbours. Besides the spectacular pictures of cosmic giants and objects too far to see from Earth's telescopes, it offered the most profound scientific and religious insight, called the PBD. To this, both science and religion alike reply: 'Oh, my God!'.

\section{Acknowledgements Competing interests}

The author declares that he has no financial or personal relationships that may have inappropriately influenced him in writing this article. 


\section{Author's contributions}

W.B. is the sole author of this article.

\section{Ethical considerations}

This article followed all ethical standards for research without direct contact with human or animal subjects.

\section{Funding information}

This research received no specific grant from any funding agency in the public, commercial or not-for-profit sectors.

\section{Data availability}

Data sharing is not applicable to this article as no new data were created or analysed in this study

\section{Disclaimer}

The views and opinions expressed in this article are those of the author and do not necessarily reflect the official policy or position of any affiliated agency of the author.

\section{References}

Barbour, I.G., 1971, Issues in science and religion, Harpercollins, London.

Beukes, C.J. \& Koekemoer, J.H., 1993, 'Metafoor, teologie, verbeelding:'n Postmoderne beskouing', HTS Teologiese Studies/Theological Studies 49(3), 595-608. https:// doi.org/10.4102/hts.v49i3.2510

Camus, A., 2000, The myth of Sisyphus, transl. J. O’Brien, Penguin Classics, London.

Cummings, L., 2017, 'Science and the religious rhetorics of the ineffable: A comparison between two cosmoses', Res Rhetorica 4(2), 15-30. https://doi.org/10.29107/rr2017.2.2

Dawkins, R., 2003, 'I: The science of religion; II: The religion of science', in The Tanner Lectures on Human Values, 19-20 November 2003, pp. 1-36, Harvard University.

Du Toit, P.W. \& Spangenberg, I.J.J., 2002, 'Kerk en teologie in die postmoderne tyd' HTS Teologiese Studies/Theological Studies 58(3), 1134-1153. https://doi. org/10.4102/hts.v58i3.591

Gleiser, M., 2014, The island of knowledge: The limits of science and the search for meaning, Basic Book, New York, NY.

Green, E., 2011, 'A primer in interdisciplinarity: J. Wentzel van Huyssteen and the postfoundational approach', Toronto Journal of Theology 27(1), 27-36. https://doi. org/10.3138/tjt.27.1.27
Holley, C. \& Shearing, C., 2017, 'Thriving on a pale blue dot', in C. Holley \& C. Shearing (eds.), Criminology and the Anthropocene, pp. 1-24, Routledge, London.

Johnson, K.A., Moon, J.W., Okun, M.A., Scott, M.J., O'Rourke, H.P., Hook, J.N. et al., 2019, 'Science, God, and the cosmos: Science both erodes (via logic) and promotes (via awe) belief in God', Journal of Experimental Social Psychology 84, 103826. https://doi.org/10.1016/j.jesp.2019.103826

Loubser, G., 2015, 'Becoming transdisciplinary theologians: Wentzel van Huyssteen, Paul Cilliers and Constantine Stanislavski', HTS Teologiese Studies/Theological Studies 71(3), 1-9. https://doi.org/10.4102/hts.v71i3.2901

MacCormac, E.R., 1975, 'Scientific and religious metaphors', Religious Studies 11(4), 401-409. https://doi.org/10.1017/S0034412500008738

MacCormac, E.R., 1983, 'Religious metaphors: Mediators between biological and cultural evolution that generate transcendent meaning', Zygon 18(1), 45-65. https://doi.org/10.1111/j.1467-9744.1983.tb00497.x

Peacocke, A., 2004, 'The future for theology in a scientific age', Cons-Ciencias 2, 391-408.

Peterson, G.R., 2008, 'Uniqueness, the image of God, and the problem of method: Engaging Van Huyssteen', Zygon 43(2), 467-474. https://doi.org/10.1111/j.14679744.2008.00928.x

Raman, V.V., 2004, 'Science and religion for the 21st century', Cons-Ciencias 2, 409-422.

Reinstorf, D.H., 2003, 'The resurrection of metaphor: A personal testimony', Acta Patristica et Byzantina 14(1), 186-204. https://doi.org/10.1080/10226486.2003. 11745724

Ruse, M., 2005, 'Darwinism and mechanism: Metaphor in science', Studies in History and Philosophy of Biological and Biomedical Sciences 36, 285-302. https://doi. org/10.1016/j.shpsc.2005.03.004

Sagan, C., 1994, Pale Blue Dot: A vision of the human future in space, Random House, New York, NY.

Sartre, J.-P., 2000, Nausea, transl. R. Baldick, Penguin Classics, London.

Scheitle, C.P. \& Ecklund, E.H., 2015, 'The influence of science popularizers on the public's view of religion and science: An experimental assessment', Public Understanding of Science 26(1), 25-39. https://doi.org/10.1177/0963662515588432

Simpson, G. \& O'Reilly, S., 2014, Overcoming dualism: The crucial dialogue between science and religion, viewed 14 May 2020, from https://www.researchgate.net/ publication/265232271_Overcoming_Dualism_The_Crucial_Dialogue_Between_ Science_and_Religion.

Tracy, D., 1978, 'Metaphor and religion: The test case of Christian texts', Critical Inquiry 5(1), 91-106. https://doi.org/10.1086/447974

Van Huyssteen, J.W., 1988a, 'Beyond dogmatism: Rationality in theology and science', HTS Theological Studies 44(4), 847-863. https://doi.org/10.4102/hts. v44i4.2243

Van Huyssteen, J.W., 1988b, 'Experience and explanation: The justification of cognitive claims in theology', Zygon 23(3), 247-260. https://doi.org/10.1111/j.1467-9744. 1988.tb00631.x

Van Huyssteen, J.W., 2006, 'When our bodies do the thinking, theology and science converge', American Journal of Theology \& Philosophy 27(2), 127-153. https:// doi.org/10.1111/j.1467-9744.1988.tb00631.x

Van Huyssteen, J.W., 2010, 'What makes us human? The interdisciplinary challenge to theological anthropology and christology', Toronto Journal of Theology 26(2) 143-160. https://doi.org/10.3138/tjt.26.2.143

Wheeler, D., 2017, Religious naturalism: A theology for UU humanists, viewed 14 May 2020 , from $\mathrm{https} / / /$ blog.unitedseminary.edu/the-canvas/religious-naturalism-atheology-for-uu-humanists-part-i. 